\title{
Closed-Loop PI Control of an Organic Rankine Cycle for Engine Exhaust Heat Recovery
}

\author{
Wen Zhang, Enhua Wang *, Fanxiao Meng, Fujun Zhang and Changlu Zhao
}

School of Mechanical Engineering, Beijing Institute of Technology, Beijing 100081, China; zhangwen9687@163.com (W.Z.); mfxbit@163.com (F.M.); zfj123@bit.edu.cn (F.Z.); clzhao@bit.edu.cn (C.Z.)

* Correspondence: wangenhua@bit.edu.cn; Tel.: +86-10-6891-3637

Received: 1 July 2020; Accepted: 23 July 2020; Published: 24 July 2020

\begin{abstract}
The internal combustion engine (ICE) as a main power source for transportation needs to improve its efficiency and reduce emissions. The Organic Rankine Cycle (ORC) is a promising technique for exhaust heat recovery. However, vehicle engines normally operate under transient conditions with both the engine speed and torque varying in a large range, which creates obstacles to the application of ORC in vehicles. It is important to investigate the dynamic performance of an ORC when matching with an ICE. In this study, the dynamic performance of an ICE-ORC combined system is investigated based on a heavy-duty diesel engine and a $5 \mathrm{~kW}$ ORC with a single-screw expander. First, dynamic simulation models of the ICE and the ORC are built in the software GT-Power. Then, the working parameters of the ORC system are optimized over the entire operation scope of the ICE. A closed-loop proportional-integral (PI) control together with a feedforward control is designed to regulate the operation of the ORC during the transient driving conditions. The response time and overshoot of the PI control are estimated and compared with that of the feedforward control alone. The results based on the World Harmonized Transient Cycle (WHTC) indicate that the designed closed-loop PI control has a shorter response time and a better trace capacity during the dynamic processes. The average output power and thermal efficiency during the WHTC cycle are improved by $3.23 \%$ and $2.77 \%$, respectively. Compared with the feedforward control alone, the designed PI control is more suitable for practical applications.
\end{abstract}

Keywords: Organic Rankine Cycle; internal combustion engine; transient simulation; PI control; feedforward control; single-screw expander

\section{Introduction}

In recent years, although a variety of new energy sources are emerging, internal combustion engine (ICE) is still a main power source for vehicles. The increasing energy crisis and environmental pollution problems have attracted attentions from all over the world. Therefore, most countries have promulgated stricter emission regulations and energy laws. At the same time, improving the efficiency of ICE has been continuously investigated. Only about one third of the energy released by the fuel combustion of an ICE is used in propelling the vehicle, and the remaining energy is wasted in various ways in the form of heat. A promising approach to enhance the efficiency of ICE is to recover the waste heat and convert it to power [1].

The Organic Rankine Cycle (ORC) is an effective method, which can recover the waste heat of ICEs, such as exhaust heat energy, cooling water energy [2]. Proper working fluid is helpful for the performance improvement of an ORC system. Many investigations have discussed working fluid selection of ORC systems. Roy et al., compared the performances of three different working fluids (R12, R123, and R134a) for converting low-grade heat energy. The results showed that R123 had the highest efficiency and power output [3]. Fang et al., considered four organic working fluids 
(toluene, decane, R245fa, and R123) and their zeotropic mixtures, and analyzed their thermodynamic and thermoeconomic performances. The results showed that pure working fluid with a higher critical temperature possessed a better performance. As for the zeotropic working fluid, the mixture of decane/toluene with a mass fraction of $0.1 / 0.9$ had the best thermoeconomic performance [4]. Wang et al., investigated nine pure working fluids (R245fa, R24ca, R236ea, R141b, R123, R114, R113, R11, and Butane) for two types of ORC systems. With regard to the optimal working region, performance, and environmental impacts, R245fa and R245ca were better than the other fluids for engine waste heat recovery [5]. Thurairaja et al., studied the thermodynamic performances of 82 working fluids for heat sources with different temperature ranges and tried to find the most suitable one for each temperature range [6]. Papadopoulos et al., presented a novel approach to the selection of optimal fluids based on group contribution methods, which could identify the best fluid with optimal comprehensive performance for an ORC system [7].

A simple ORC system basically consists of four components: an evaporator, a condenser, a pump, and an expander. However, more complicated configurations were designed to improve the system performance [8-10]. Braimakis et al., designed three configurations including an open preheater regenerative ORC and two closed preheater regenerative ORCs with backward/forward bleed condensate circulation. Optimization results indicated that these configurations possessed a higher efficiency compared to the standard ORC [11]. Al-Mousawi et al., built and simulated four different configurations, which used as a bottoming cycle integrated with an adsorption cooling system (topping cycle). Three different adsorption pairs for the topping cycle and three working fluids for the bottoming cycle were selected separately. Comparisons of their efficiencies showed that ORC had a great potential to reclaim low-grade heat energy [12]. Sadeghi et al., developed three configurations of ORC powered by a geothermal source, including the simple ORC, the parallel two-stage ORC and the series two-stage ORC. The performances of different working fluids such as R407A, R245fa, and their zeotropic mixtures were compared. The results showed that the series two-stage ORC using R407A represented a better performance and gained $877 \mathrm{~kW}$ of net power after a multi-objective optimization [13].

Because the working parameters of an ORC have great impacts on the system performance, many researchers have devoted their efforts to analyze the influences of these parameters [14-16]. Tian et al., established an ORC model used in an ICE and discussed the influences of the cycle parameters including the expansion ratio and the evaporating pressure on the thermal efficiency [17]. Karellas et al., explored the design of the heat exchanger for ORC. They investigated different heat exchanger parameters such as the total surface area, the heat transfer coefficient, the heat transfer efficiency, the operating pressure. A method was suggested for calculation and dimensional design of the heat exchanger [18]. Abam et al., considered various ORC configurations with several different working fluids and estimated the effects of the turbine inlet temperature, the evaporator pressure, and the mass flow rate on the exergy destruction and the system power output [19].

For some applications, the ORC system may operate under transient conditions for a long time, which needs a controller to assure high security, stability, and efficiency. In these applications, the dynamic control is critical. Many investigations were focused on the system modeling and dynamic control of ORC systems [20-27]. Wei et al., compared the performances of two dynamic ORC models based on the moving boundary and discretization methods. It was found that both models could predict the system accurately with an error of less than $5 \%$. However, the moving boundary model was more acceptable for control applications because it was less complex [28]. Xu et al., built an engine model in GT-Power together with an ORC system while the control strategy was designed in Matlab/Simulink. The system parameters such as the vapor temperature and the evaporation pressure could be accurately predicted within an error less than 3\% [29]. Zhao et al., employed a particle swarm optimization to improve the performance of an ICE-ORC combined system via adjusting the exhaust valve timing, the injection timing, the expander speed, and the pump speed. The output power and the brake-specific fuel consumption were improved by about 3\% after optimization [30]. Liu et al., built an 
ICE-ORC model in GT-Power and a feedforward control strategy was implemented in Matlab/Simulink. The speeds of the expander and the pump were selected as the control variables [31]. Yebi et al., proposed a real-time control algorithm based on a non-linear model predictive control (MPC) for an ORC system. Compared with the traditional proportional-integral-derivative (PID) control, the power production and the recovered thermal energy were increased by $12 \%$ and $9 \%$, respectively [32]. Liu et al., designed two MPC control methods including a linear MPC and a non-linear MPC for controlling an ORC test rig to recover the waste heat from the tailpipe and the EGR path of an engine. Both the simulation and experiment results showed that the system with the MPC control methods displayed a better performance and a faster temperature response [33].

Advanced control strategy such as MPC can regulate the operation parameters of an ORC with a high accuracy. However, it may be too complicated to be implemented in a control system in practical applications. Feedforward control such as presented in our previous study [29] is simple enough whereas it can only compensate measurable disturbances. The operation conditions of a vehicle engine normally vary in a large range and many disturbances are not predictable. Therefore, it is necessary to develop a control strategy that can be used in practical real-time control and the dynamic performance and robustness are acceptable. In this study, a closed-loop proportional-integral (PI) control together with a feedforward control is designed for an ORC system bottoming with a heavy-duty diesel engine. A dynamic simulation model of the ICE-ORC combined system is established in GT-Power. First, the optimal target values for the operation parameters of the ORC system are determined based on the simulation model of the combined system. Then, the performance of the closed-loop control strategy is compared with the feedforward control via a step response simulation. Finally, the dynamic performances of the ORC system using these two different control strategies are compared based on the World Harmonized Transient Cycle (WHTC). The results of this study can provide a reference for the practical application of ORC systems for engines which need to operate under various conditions.

\section{System Modeling}

The operation conditions of vehicle engines are very complicated. When an ORC is used to recover the exhaust heat, it is difficult to match the ORC system with the engine over the entire driving conditions. In this study, a methodology for the design of an ORC controller is proposed for engine waste heat recovery. A flow chart of the design procedure is shown in Figure 1. First, a high-fidelity dynamic model is set up for the engine in GT-Power [34] and experimental data are used to calibrate and validate the engine model. Then, a dynamic model of the simple ORC is designed in GT-Power. The optimal operation parameters of the ORC system are determined under various steady conditions of the engine and four maps are obtained for the evaporation pressure, the mass flow rate of the working fluid, the expander speed, and the pump speed. Subsequently, a dynamic control strategy is designed in Matlab/Simulink and an ICE-ORC combined system is established. In this study, a PI control together with a feedforward control is setup using the evaporation pressure and the mass flow rate of the working fluid as the controlled variables. The parameters of the PI controller are calibrated based on a step response. Finally, the control performance of the designed PI control is investigated based on a transient driving cycle. This methodology can provide a convenient and cheap method for the design of ORC controller. Thus, a lot of time and cost can be saved. 


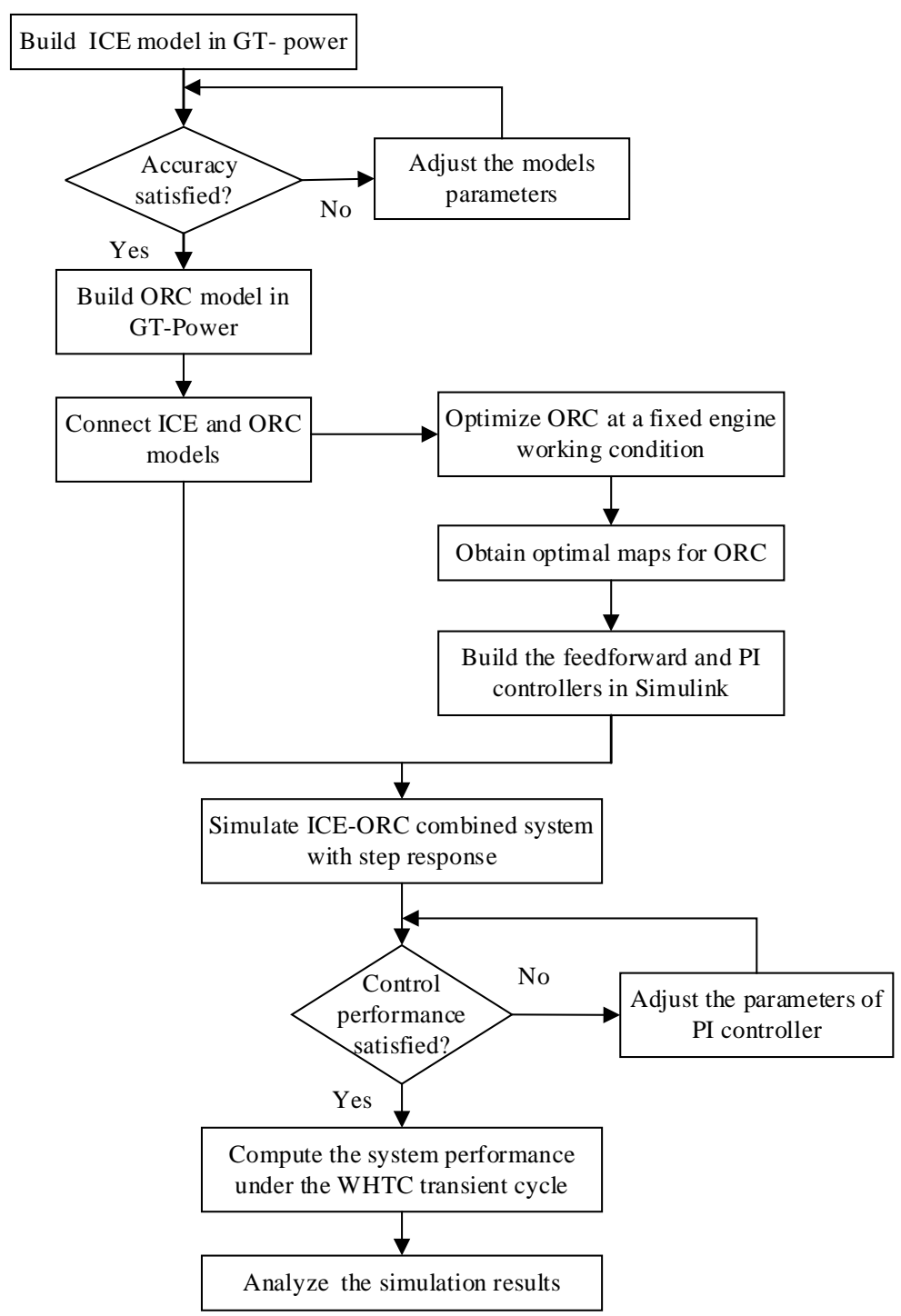

Figure 1. Flow chart of the design procedure for the Organic Rankine Cycle (ORC) controller matched with a vehicle engine.

To evaluate the transient performance, a dynamic model of an ICE-ORC combined system is established. The model is divided into two parts: the ICE and the ORC system. The ICE model is built in GT-Power. The heat energy of the exhaust gases is sent to the ORC system as the heat source and the amount of the exhaust energy mainly depends on the mass flow rate and the temperature of the exhaust gases from the ICE. The second part is the ORC system, which functions as a bottoming cycle and converts the exhaust energy to useful work. In this study, a simple ORC configuration is used.

\subsection{Internal Combustion Engine (ICE) Model}

The ICE model is based on a heavy-duty turbocharged diesel engine and its main technical parameters are listed in Table 1. 
Table 1. Technical parameters of the engine.

\begin{tabular}{ccc}
\hline Parameter & Value & Unit \\
\hline Displacement & 11.12 & $\mathrm{~L}$ \\
Bore & 125 & $\mathrm{~mm}$ \\
Stroke & 156 & $\mathrm{~mm}$ \\
Compression ratio & 16.4 & - \\
Rated power & 190 & $\mathrm{~kW}$ \\
Max. torque & 1859 & $\mathrm{Nm}$ \\
\hline
\end{tabular}

Because the structure and working conditions of the ICE are very complex, some necessary simplifications are assumed for the ICE model:

1. The model is independent of specific spatial coordinates of the system;

2. The working media in the cylinder is treated as ideal gas, and its state is governed by the conservation equations of mass and energy together with the equation of state of ideal gas;

3. The injected fuel burns completely and reaches the thermodynamic equilibrium state at each instant in the cylinder.

A quasi-steady 1D model is built in GT-Power, which can be expressed by several differential equations. The ICE model built in GT-power is simulated under the full-load conditions. The results are compared with the measured data from an engine test and shown in Figure 2. It can be seen that the engine power, the engine torque, and the brake-specific fuel consumption (BSFC) are in good agreement with the experimental data. The deviations for most working conditions are less than $10 \%$. Therefore, the accuracy of the ICE model is validated and can be used for the simulation of the ICE-ORC combined system.

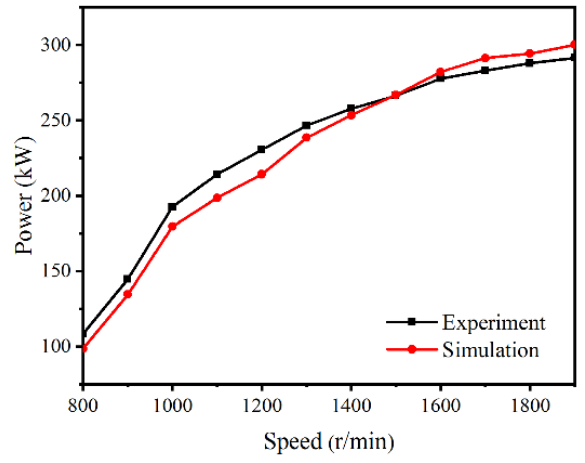

(a)

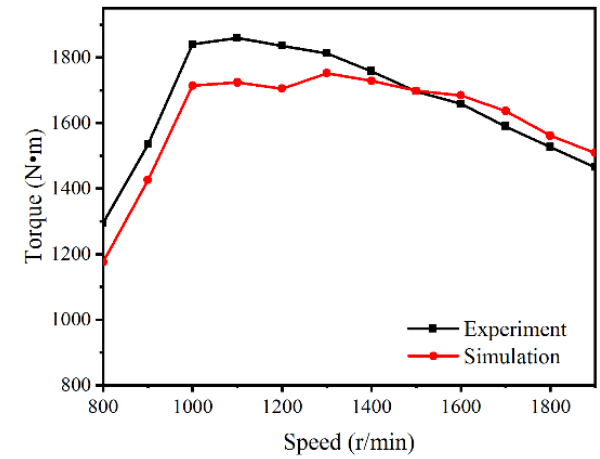

(b)

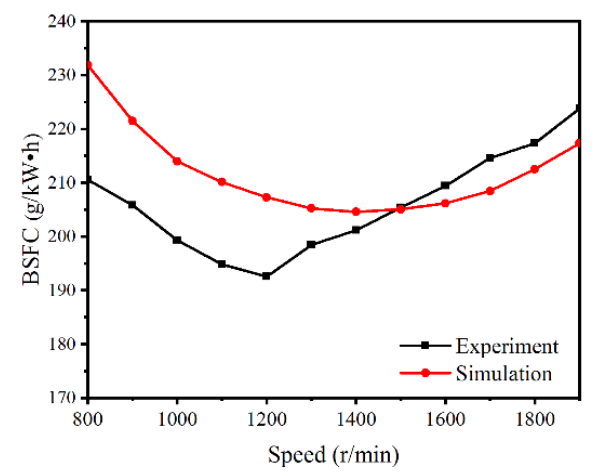

(c)

Figure 2. Comparison between the simulation and experimental results of the internal combustion engine (ICE): (a) power; (b) torque; (c) brake-specific fuel consumption (BSFC). 


\subsection{Organic Rankine Cycle (ORC) Model}

There are various configurations for ORC systems, such as the simple ORC, the ORC with a regenerator, the ORC with a reheater, the dual-loop ORC, and so on. Considering the complexity of the device, this study adopts the simple ORC, which is mainly composed of an evaporator, a condenser, an expander, and a pump. Figure 3 shows the main structure of the simple ORC.

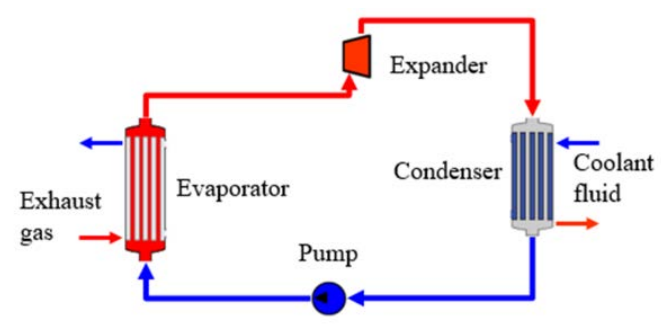

Figure 3. Schematic of the simple ORC.

The evaporator is used to absorb heat from the exhaust gases so that the working fluid can be evaporated from a liquid state to a gaseous state. The high-pressure gaseous working fluid is transmitted to the expander to generate work. The condenser is used to condensate the working fluid to a low-pressure liquid state after expansion. The pump pressurizes the working fluid and outputs to the evaporator for the next cycle. Normally, the organic working fluid undergoes three different phases such as liquid, two-phase, and gaseous states inside the evaporator and the condenser. The working fluid of the ORC system is R245fa. The coolant of the condenser is a mixture of water and glycol with a mass fraction of 50/50. The properties of R245fa and the coolant are determined by the property module in GT-Power. The main parameters for the components of the ORC system under the nominal condition are listed in Table 2.

Table 2. Main nominal parameters of the ORC components.

\begin{tabular}{ccc}
\hline Parameter & Value & Unit \\
\hline Expander speed & 2400 & $\mathrm{r} / \mathrm{min}$ \\
Expander output power & 8.0 & $\mathrm{~kW}$ \\
Expander efficiency & 0.55 & \\
Pump speed & 2500 & $\mathrm{r} / \mathrm{min}$ \\
Pump mass flow rate & 0.325 & $\mathrm{~L} / \mathrm{s}$ \\
Pump efficiency & 0.80 & \\
Evaporator type & Shell-and-tube & \\
Evaporator heat transfer area & 2.88 & $\mathrm{~m}^{2}$ \\
Condenser type & Plate & \\
Condenser heat transfer area & 2.7 & $\mathrm{~m}^{2}$ \\
\hline
\end{tabular}

For the single-phase region of the working fluid in the evaporator, the Dittus-Boelter correlation [35] is used to determine the convective heat transfer coefficient.

$$
h=0.023 \operatorname{Re}^{0.8} \operatorname{Pr}^{0.4} \frac{k}{d^{\prime}}
$$

where $h$ is the convective heat transfer coefficient, $R e$ is the Reynolds number, $\operatorname{Pr}$ is the Prandtl number, $k$ is the thermal conductivity, and $d$ is the characteristic length. 
In the two-phase region of the evaporator, the heat transfer is modelled by the Shah-Thome correlation [36] and expressed by:

$$
\begin{gathered}
N u_{l}=0.023 \cdot \operatorname{Re}_{l}{ }^{0.8} \cdot \operatorname{Pr}_{l}{ }^{0.4}, \\
h=N u_{l} \cdot(1-x)^{0.8} \cdot \frac{3.8 \cdot x^{0.76}(1-x)^{0.04}}{P_{r d} 0.38} \cdot \frac{k}{D^{\prime}} \\
P_{r d}=\frac{P}{P_{c r}}
\end{gathered}
$$

where $\mathrm{Nu}$ is the Nusselt coefficient, $x$ is the quality, $P$ is the operation pressure of the working fluid, and $P_{c r}$ is the critical pressure. The subscripts $l$ and $r d$ represent liquid and reduced, respectively.

In the single-phase region inside the condenser, the heat transfer coefficient is determined by Equation (5) with an exponential of 0.3 for $\operatorname{Pr}$ due to the change of viscosity of the working fluid.

$$
h=0.023 \cdot \operatorname{Re}^{0.8} \operatorname{Pr}^{0.3} \cdot \frac{k}{d}
$$

In the two-phase region of the condenser, the heat transfer is modelled by the Yan-Lin correlation [37] and expressed by:

$$
\begin{gathered}
h=1.926 B o_{e q}{ }^{-0.3} \operatorname{Re}_{e q}{ }^{0.5} \operatorname{Pr}_{l}^{1 / 3} \cdot\left(1-x+\sqrt{\rho_{l} / \rho_{g}}\right) \cdot \frac{k}{D^{\prime}} \\
R e_{e q}=\frac{\rho V\left(1-x+x \sqrt{\rho_{l} / \rho_{g}}\right) D}{\mu_{l}}, \\
B o=\frac{q}{\dot{m} \cdot\left(h_{v}-h_{f}\right)},
\end{gathered}
$$

where $\rho$ is the fluid density, $D$ is the reference length, $q$ is the heat flow rate, and $\mu$ is the dynamic viscosity.

The high-temperature gaseous working fluid from the outlet of the evaporator flows into the expander and changes to a low-pressure state, propelling the expander to spin and drive a generator to produce electricity. In this study, a single-screw expander is employed, which is the same as in reference [29]. The measured data by [38] are used for the modeling process in GT-Power. The pump is responsible for pressurizing the low-temperature liquid working fluid and then delivering it to the evaporator. The data in reference [29] is used to model the pump. Finally, the ICE-ORC combined system is setup in GT-Power and Figure 4 shows the model connection. The exhaust gases flow out of the turbine of the ICE and then enter into the evaporator of the ORC. In the GT-Power software, because the calculation algorithm of the ICE model is different from that of the ORC model, a splitter module is inserted between the turbine and the evaporator to synchronize the calculation process when coupling the ICE with the ORC. To control the operation of the ORC during the transient conditions, a Simulink module is added to implement the control strategy. The engine speed, the engine torque, the mass flow rate, and the exhaust temperature are sampled by the controller. According to the rotation speed and torque of the ICE, the target speeds of the single-screw expander and the pump are determined by the control algorithm. Then, these signals are sent to the ORC model to control the speeds of the single-screw expander and the pump. 


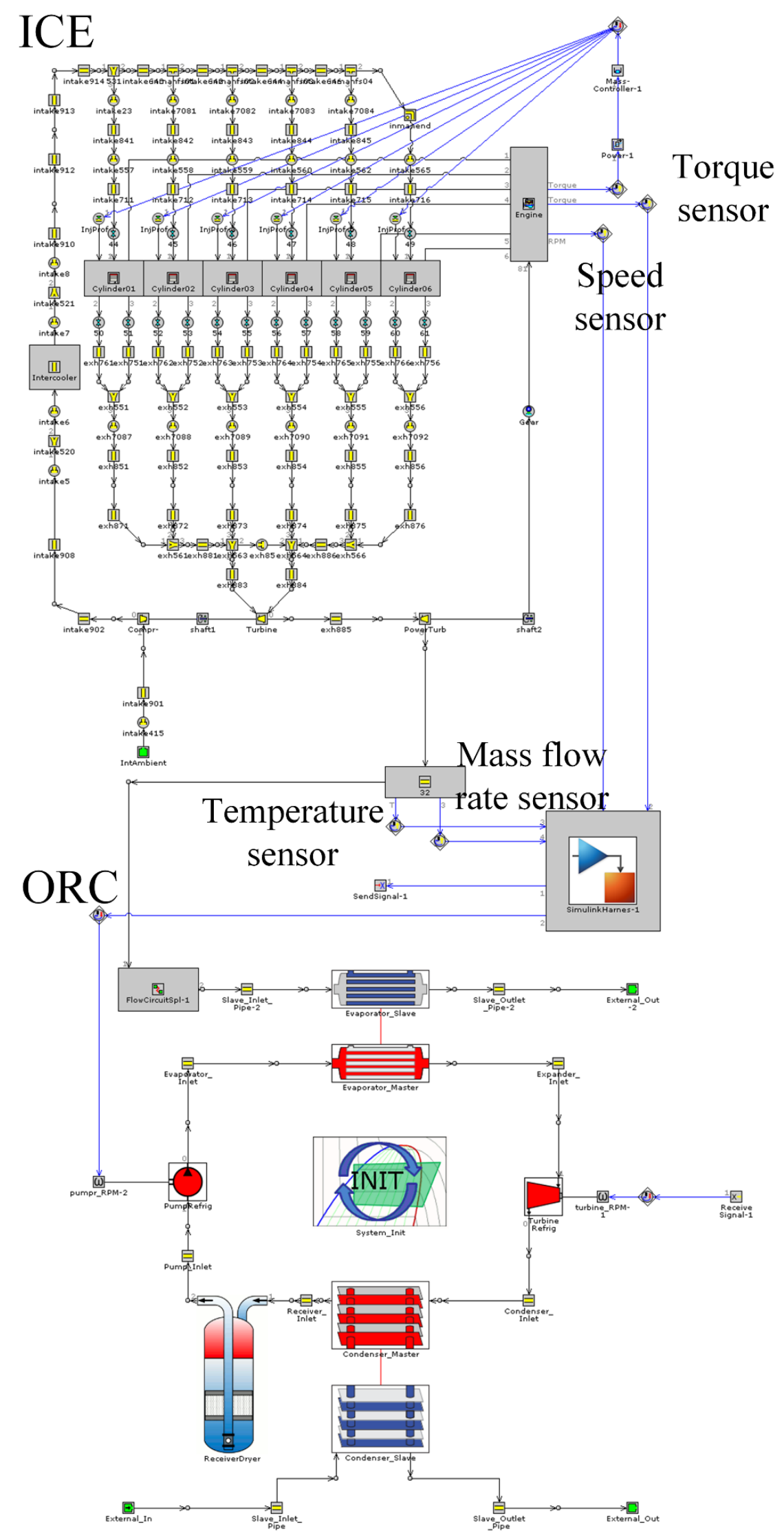

Figure 4. ICE-ORC combined system model built in GT-Power. 


\section{Performance of ICE-ORC Combined System}

The performance of the ORC system is mainly affected by two factors: the first is the amount of heat energy provided by the exhaust gases of the ICE, which is decided by the exhaust temperature and the exhaust mass flow rate; the second factor is the operating parameters of the ORC system, for example, the evaporation pressure, the evaporation temperature, the mass flow rate of the working fluid, etc. These parameters are normally controlled by the expander speed and the pump speed. To study the operation characteristics of the ICE-ORC combined system under dynamic conditions, it is necessary to estimate the match performance when the engine operating under different steady conditions. The allowable working speed of the engine is $800-1900 \mathrm{r} / \mathrm{min}$. Under the low-speed region, the exhaust mass flow is too small, which has not enough exhaust energy to drive the ORC system. Hence, the working fluid at the outlet of the evaporator cannot be evaporated completely. If the working fluid enters the expander in a liquid-gaseous two-phase state, it will not be helpful for the durability of the expander and may cause damages to the expander vanes. In this study, the engine performance data are measured across the entire working scope. The engine speed of the ICE is set from $800 \mathrm{r} / \mathrm{min}$ to $1900 \mathrm{r} / \mathrm{min}$ in an interval of $100 \mathrm{r} / \mathrm{min}$. The engine load of the ICE is set from $10 \%$ to $100 \%$ in an interval of $10 \%$. Subsequently, 63 working points of the ICE are selected and the ORC performance is optimized under each working point of the ICE.

When the engine operates at a fixed point, the output performance of the ORC system will be affected by the working parameters of the ORC such as the mass flow rate, the evaporation pressure, the condensation pressure, etc., which can be regulated by the speeds of the expander and the pump. In this study, the operation range of the expander speed is set to $900-2400 \mathrm{r} / \mathrm{min}$ and the pump speed is set to 100-2500 r/min. Here, the working point with an engine speed of $1500 \mathrm{r} / \mathrm{min}$ and an engine load of $80 \%$ is used as an example to illustrate the optimization process of the ORC system when matching with the ICE. Table 3 lists the working parameters of the ICE at this point, which are used as the input to the ORC system.

Table 3. Measured data when the engine operates with an engine speed of $1500 \mathrm{r} / \mathrm{min}$ and an engine load of $80 \%$.

\begin{tabular}{ccc}
\hline Parameter & Value & Unit \\
\hline Engine speed & 1500 & $\mathrm{r} / \mathrm{min}$ \\
Torque & 1410 & $\mathrm{Nm}$ \\
Power & 221 & $\mathrm{~kW}$ \\
Exhaust temp. & 703 & $\mathrm{~K}$ \\
Exhaust flow rate & 0.349 & $\mathrm{~kg} / \mathrm{s}$ \\
\hline
\end{tabular}

When the engine operates under a fixed point, the expander speed and the pump speed are tuned and the performance of the ORC system is recorded. Figure 5 shows the results when the engine operates at $1500 \mathrm{r} / \mathrm{min}$ and $80 \%$ load. For a fixed working point of the engine, the available exhaust energy maintains at a certain value and the allowable mass flow rate of the working fluid needs to match with it. It can be seen that the range of the rotation speed of the pump is not covered the entire working scope of the pump. If the mass flow of the organic working fluid at the cold side of the evaporator is too small, the exhaust energy from the ICE cannot be fully utilized and the temperature of the working fluid will exceed the upper limit. On the other hand, if the mass flow of the working fluid is too high, the organic working fluid at the outlet of the evaporator cannot completely evaporate and the quality is less than 1 , which is not conducive to the operation of the ORC system. Both situations are abnormal and should be avoided. The flow rate of the working fluid is mainly determined by the rotation speed of the positive displacement pump. Therefore, the rotation speed range of the pump is narrow for a fixed engine working condition. In this case, the allowable pump speed ranges from $1750 \mathrm{r} / \mathrm{min}$ to $2500 \mathrm{r} / \mathrm{min}$. Meanwhile, the expander speed has a great influence on the performance of the ORC. In this case, its working range can cover the entire scope as 900-2400 r/min. 


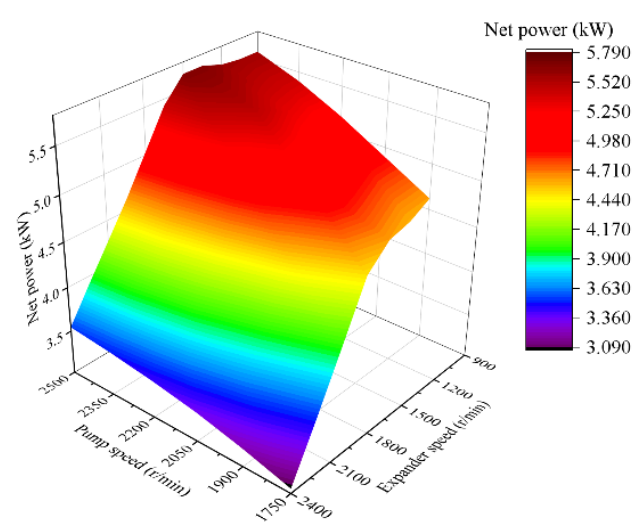

(a)

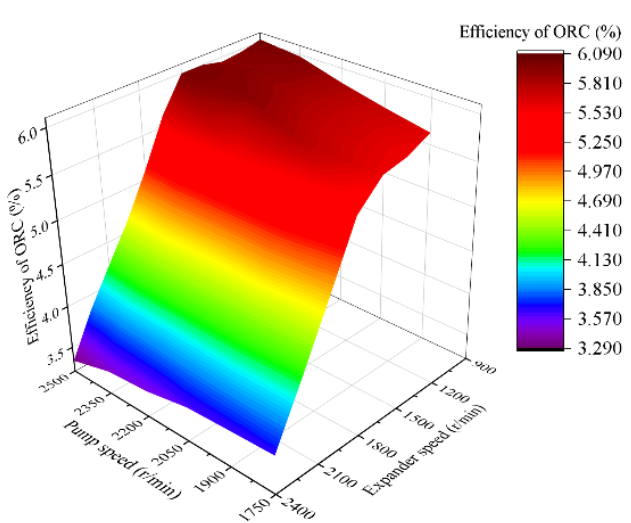

(b)

Figure 5. ORC performance as a function of expander speed and pump speed when the engine operates at $1500 \mathrm{r} / \mathrm{min}$ and $80 \%$ load: (a) net power; (b) thermal efficiency.

Figure 5a shows the net power of the ORC system as a function of the expander speed and the pump speed, which first increases obviously with the decrease of the expander speed, then arrives the peak and slightly decreases. The optimal expander speed is in the low-speed region. With the increase of the pump speed, the net power of the ORC system increases monotonously. Under the considered working point of the ICE, the optimal working condition of the ORC when the net power maximizes is obtained with an expander speed of $1500 \mathrm{r} / \mathrm{min}$ and a pump speed of $2500 \mathrm{r} / \mathrm{min}$. The corresponding net power of the ORC system is $5.79 \mathrm{~kW}$. Figure $5 \mathrm{~b}$ shows the thermal efficiency of the ORC system. The trend is similar to that of the net power. This is because the heat transfer of the evaporator keeps almost constant. The maximum thermal efficiency reaches $6.09 \%$, which appears at the same point as the net power.

Figure 6a shows the effects of the mass flow of the working fluid and the evaporation pressure on the net power of the ORC system. The evaporation pressure has a significant influence on the net power. With the increase of the evaporation pressure, the net power rises rapidly. For the ORC system, the lower the rotating speed of the expander, the higher the evaporation pressure, the greater the enthalpy difference between the inlet and outlet of the expander, and the higher the output power, which also verifies that the net power is larger when the rotating speed of the expander is lower in Figure 5a. Under the same evaporation pressure, the net power decreases slightly with the increase of the mass flow of the working fluid.

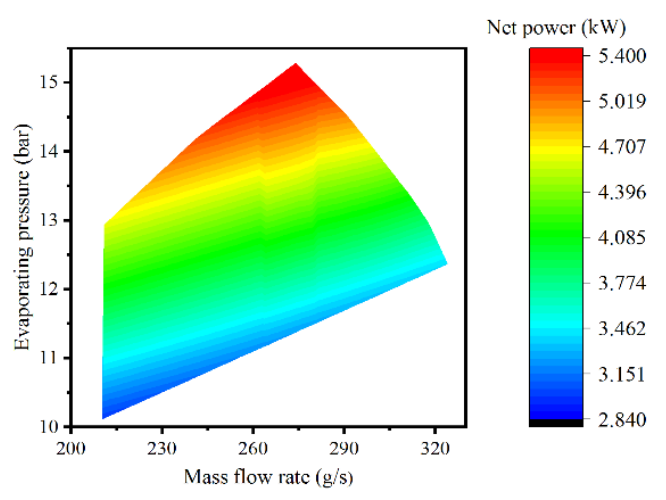

(a)

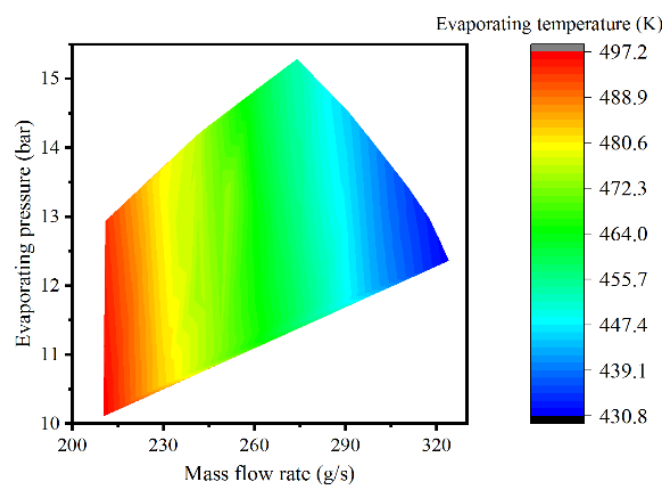

(b)

Figure 6. ORC performance as a function of evaporation pressure and mass flow rate of the working fluid when the engine operates at $1500 \mathrm{r} / \mathrm{min}$ and 80\% load: (a) net power; (b) evaporation temperature. 
Figure $6 \mathrm{~b}$ shows the influences of the evaporation pressure and the mass flow rate of the working fluid on the evaporation temperature. Here, the evaporation temperature is defined as the working fluid temperature at the outlet of the evaporator. The mass flow rate manifests a more significant impact on the evaporation temperature than the evaporation pressure. A negative correlation between the evaporation temperature and the mass flow can be found. The smaller the mass flow, the higher the evaporation temperature. Compared with Figure 6a, we can see that the higher the evaporation pressure, the better the net power. However, the net power of the ORC system is not always kept high in the region with the highest evaporation temperature, because maybe the mass flow rate of the working fluid is too small to form a high evaporation pressure, and the evaporation pressure has a greater impact on the net power of the ORC system.

The performance of the ORC system under different engine working conditions was analyzed according to the above procedure. In fact, the operation conditions of the ICE may vary frequently during the driving process, especially in the urban road conditions. Therefore, it is meaningful to investigate the ORC performance over the entire engine's working scope. In this study, 63 different working points across the entire engine operation scope were selected. The engine speed ranged from $800 \mathrm{r} / \mathrm{min}$ to $1900 \mathrm{r} / \mathrm{min}$ with an interval of $100 \mathrm{r} / \mathrm{min}$ and the engine load was between $10 \%$ and $100 \%$ with an interval of $10 \%$. The performance of the ORC system can be determined at each working point using the same procedure described as the above case. Although the optimal performances of the ORC system are different under these working points of the ICE, the overall trends of the maps are similar to those of Figures 5 and 6 . After sorting out 63 simulation cases, the optimal operation parameters of the ORC system under each case can be obtained.

Figure 7 gives the optimal results of the expander speed and the pump speed when the ORC matches the ICE over the entire engine's working scope. Comparing these two figures, it can be found that the variation trends of the optimal pump speed with the engine speed and the engine load are approximately the same as that of the expander speed. Both increase with the increase of the engine speed or the engine load. The optimal speed range of the expander is $900-1650 \mathrm{r} / \mathrm{min}$, and the optimal speed range of the pump is $250-2500 \mathrm{r} / \mathrm{min}$. Taking into account the designed operation ranges of the expander and the pump, it can be observed that the operation range of the expander is mainly located in the low- and medium-speed region, and the pump is concentrated in the high-speed region. This is because, as mentioned above, a lower expander speed can lead to a higher evaporation pressure. When the ICE operates under the conditions with a low-and-medium engine power, the optimal expander speed is about $900 \mathrm{r} / \mathrm{min}$. As the engine power increases, the exhaust energy also enlarges and the optimal expander speed increases. When the engine operates at $1900 \mathrm{r} / \mathrm{min}$ with a full load, the maximum expander speed arrives at $1650 \mathrm{r} / \mathrm{min}$. The optimal pump speed situates in the high-speed region over most of the operation scope of the engine because the exhaust energy is high enough under the medium and high engine-power conditions. In order to utilize the exhaust energy comprehensively and avoid the temperature of the working fluid exceeding the critical temperature, the mass flow of the working fluid should be increased to a high level. As a result, the pump needs to operate with a high speed. In the case of a small exhaust energy, the pump speed decreases to keep the mass flow rate smaller such that the working fluid can be evaporated completely. The red dashed lines of the two maps represent the shutdown boundary for the ORC system. The engine load is close to $10 \%$ along the red lines. At this moment, the efficiency of the ORC system is very low. When the engine operation condition is below the red line, the ORC system stops. Compared with the results of Liu et al. [29], the maps in Figure 7 display a smoother variation. The reason can be explained as follows. The exhaust energy of the engine is small in Liu's study, the optimal operation ranges of the pump and the expander locate in the low-speed regions. As a contrast, an engine with a much higher power output is considered in this study. Meanwhile, the considered engine working points are increased significantly in this study. Therefore, the operation ranges of the expander and the pump are extended significantly. 


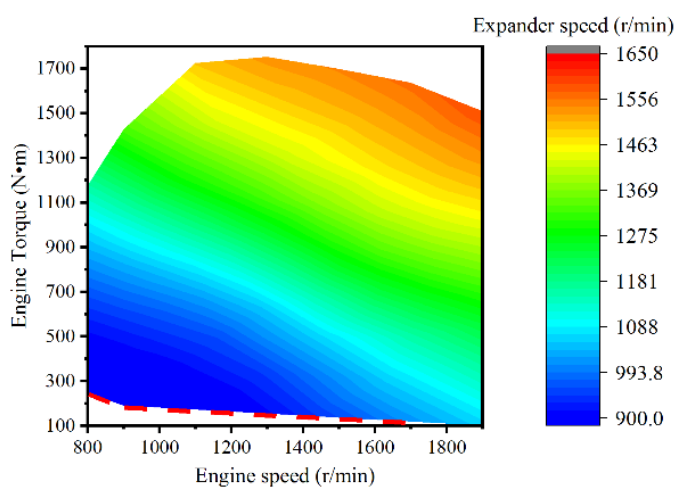

(a)

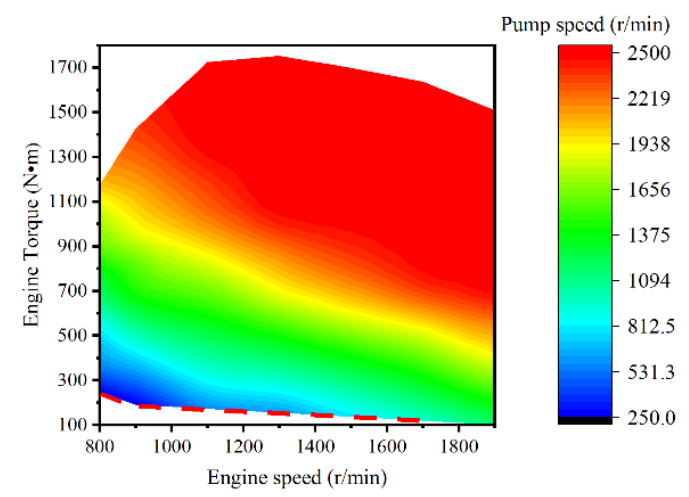

(b)

Figure 7. Optimal results of the ORC system over the entire engine's working scope: (a) expander speed; (b) pump speed.

\section{Control Strategy Design}

The operation conditions of the ICE may change rapidly because of the complexity of road conditions. A rapid variation of the state of the exhaust gases requires to adjust the operating parameters of the ORC system accordingly in order to achieve an optimal output of the ORC system. Therefore, a dynamic control strategy needs to be designed. In this study, two different control strategies including a feedforward control and a closed-loop PI control are developed and compared.

\subsection{Feedforward Control}

First, a feedforward control strategy is designed and shown in Figure 8. Feedforward control operates based on the compensation principle according to the change of disturbance or set value. When a disturbance appears, the control strategy regulates the control variables according to the change of disturbance to compensate the influence on the controlled variables. It can be applied to the cases with a frequent or large variation of the disturbance, and can be continuously maintained at the proximity of the set value theoretically. In this study, the control strategy is developed in Matlab/Simulink. The model of the ICE-ORC combined system in GT-Power outputs the signals such as the engine speed and the engine torque to the control strategy module. The feedforward control strategy determines the target values for the expander speed and the pump speed via looking up two 2D maps, which are already obtained as Figure 7 shows. A limitation block is used as a safety check for each signal. Subsequently, the target values are transmitted to the ORC model. The expander speed and the pump speed are tuned accordingly. When the ICE operates below the stop line and the exhaust energy is too small, the ORC system is shut down and the control strategy sets the rotation speeds of the expander and the pump to 0 directly. The feedforward control strategy is implemented in Matlab/Simulink and the control operation states of the ORC system can be regulated under dynamic conditions. 


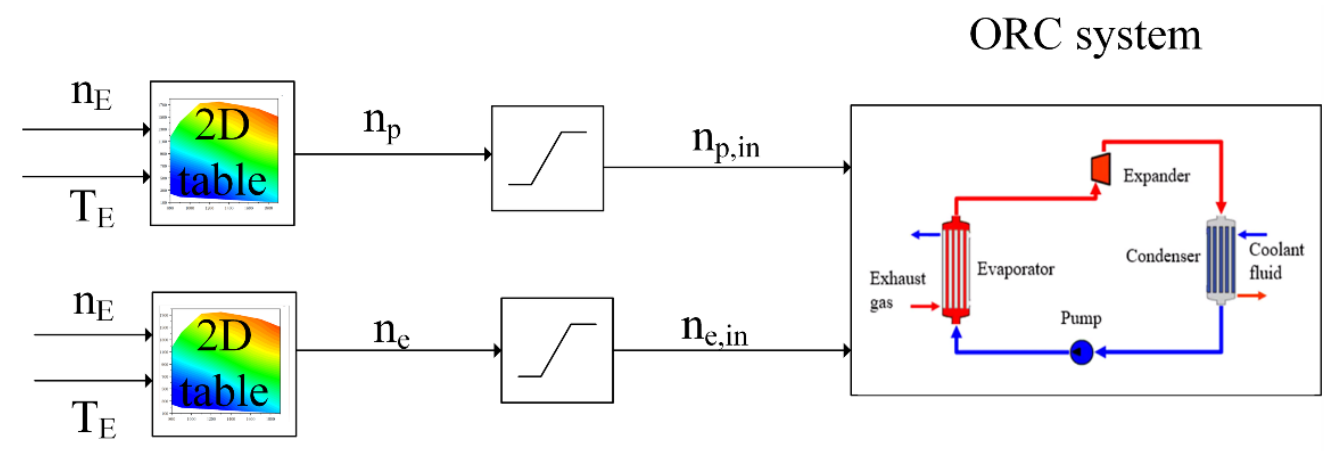

Figure 8. Designed feedforward control for the ORC system.

\subsection{Proportional-Integral (PI) Control}

Feedforward control only compensates the measurable disturbances. Compared with the feedforward control, a closed-loop feedback control can compensate all the disturbances that affect the controlled variables to a certain extent, and speed up the system response. PI control as a typical feedback control method is used for many industrial applications. In this study, a closed-loop PI control is designed together with an open-loop feedforward control to adjust the speeds of the expander and the pump. The accuracy and robustness can be improved by the PI control. In fact, a large non-linear characteristic exists over the entire working scope of the ICE-ORC combined system. A PI control alone is very difficult to calibrate the parameters of the PI controller. Meanwhile, the response time and robust performance cannot be fulfilled for all the operation conditions. Therefore, A PI control together with a feedforward control is designed in this study to overcome the shortcomings of only the feedforward control or the PI control. Hence, the advantages of both control methods can be fully utilized. The designed closed-loop PI control strategy is shown in Figure 9. In this design, PI control is combined with the feedforward control. The designed control system is a multi-input multi-output (MIMO) system. Two input variables are the mass flow rate of the working fluid and the evaporation pressure. Two output variables are the target values for the expander speed and the pump speed. In this study, the MIMO control system is decoupled to two single-input single-output (SISO) subsystems. The error between the target and measured values of the mass flow rate of the working fluid is determined and input to the PI controller 1. Meanwhile, a feedforward control calculated the optimal pump speed $n_{p}$ based on the engine speed $n_{E}$ and the engine load $T_{E}$. The final target of the pump speed is the summation of $n_{p}$ and the output of the PI controller 1. The PI controller 2 controls the expander speed according to the measured evaporation pressure and has a similar structure with the PI controller 1. 


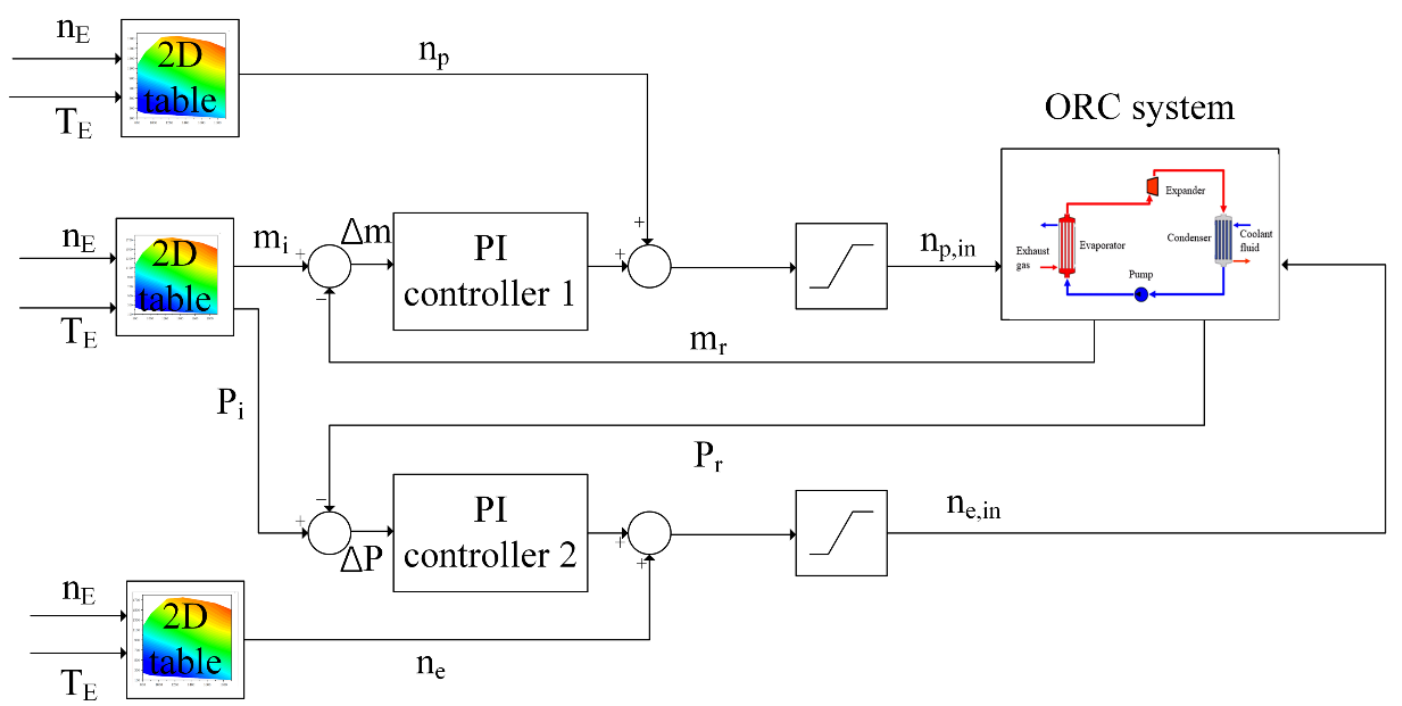

Figure 9. Designed closed-loop proportional-integral (PI) control for the ORC system.

\subsection{Step Response Comparison}

The performances of the designed feedforward control and the PI control are compared based on a step response. The initial parameters of the ORC system are listed in Table 4 . The engine starts at $0 \mathrm{~s}$ and operates steadily at Condition 1 with an engine speed of $1100 \mathrm{r} / \mathrm{min}$ and an engine torque of $853 \mathrm{Nm}$ after $150 \mathrm{~s}$. Then, it steps to Condition 2 with an engine load $853 \mathrm{Nm}$ while the engine speed keeps constant at $150 \mathrm{~s}$. At $300 \mathrm{~s}$, the operation condition of the engine steps back to Condition 1 . At Condition 1, the target values of the mass flow rate and the evaporation pressure for the ORC system are $164 \mathrm{~g} / \mathrm{s}$ and 8.4 bar, respectively. At Condition 2, the mass flow rate changes to $234 \mathrm{~g} / \mathrm{s}$, and the evaporation pressure is 10.8 bar.

Table 4. Initial conditions for the ORC system.

\begin{tabular}{ccc}
\hline Parameter & Value & Unit \\
\hline R245fa temperature & 300 & $\mathrm{~K}$ \\
R245fa weight & 20 & $\mathrm{~kg}$ \\
Coolant temperature & 296.15 & $\mathrm{~K}$ \\
Coolant mass flow & 190 & $\mathrm{~L} / \mathrm{min}$ \\
Coolant pressure & 1 & $\mathrm{bar}$ \\
Wall temperature of the heat exchangers & 300 & $\mathrm{~K}$ \\
\hline
\end{tabular}

Figure 10a shows the profiles of the mass flow rate of the working fluid. The two control strategies designed have a high accuracy and can track the set values well during the transient working process. Generally, the performance of the PI control is superior to the feedforward control in terms of the response time and overshoot. In the start-up phase, in order to respond more quickly, there is an $10 \%$ overshoot in the mass flow rate by the PI control, and the system becomes stable at about $50 \mathrm{~s}$. The feedforward control takes much longer and the system is stable after about $120 \mathrm{~s}$. For the first step from Condition 1 to Condition 2, it takes about $30 \mathrm{~s}$ for the PI control to achieve the new steady state, which is also far faster than that of the feedforward control. For the second step from Condition 2 back to Condition 1, the response time of the PI control is close to the feedforward control. However, the overshoot amplitude of the PI control is much smaller, only half of the feedforward control. 


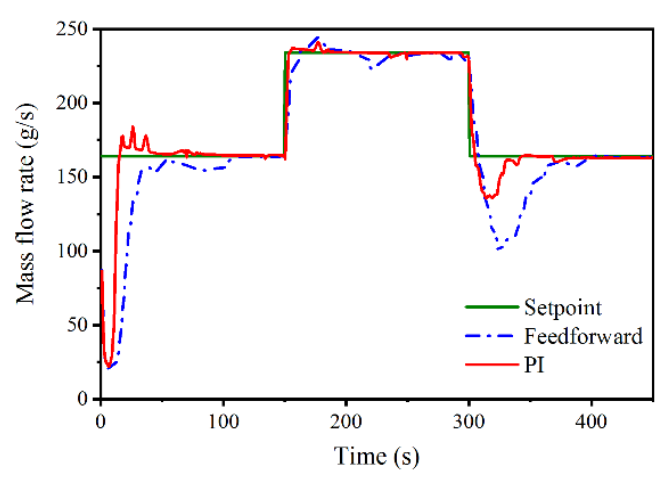

(a)

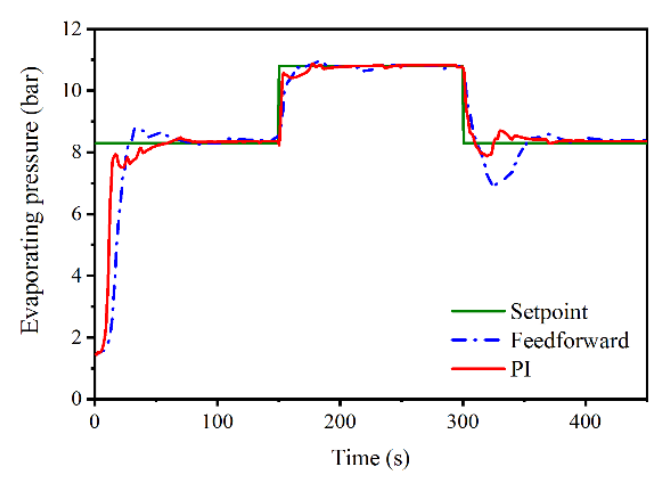

(b)

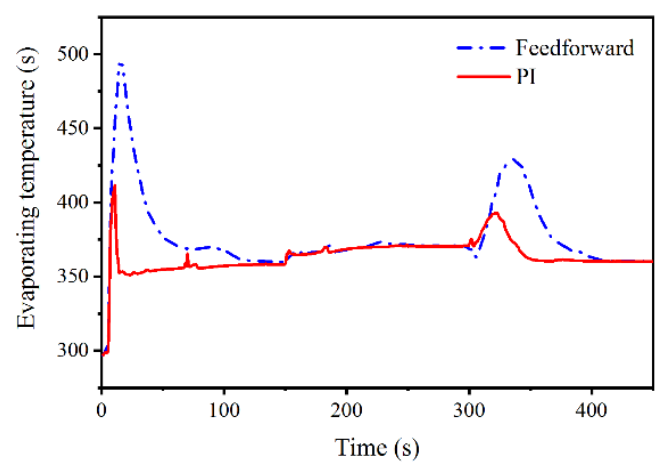

(c)

Figure 10. Step response performance comparison between the feedforward control and the closed-loop PI control: (a) mass flow rate of the working fluid; (b) evaporating pressure; (c) evaporating temperature.

The results for the evaporation pressure of the ORC system is shown in Figure 10b. Basically, the difference between the two control strategies is relatively small in the upward step process. The PI control takes advantage of a quick response time, which is about $8 \mathrm{~s}$ faster than that of the feedforward control. However, in the downward step process, the overshoot amplitude and the response time of the PI control are both better than those of the feedforward control. The variation of the evaporation temperature is shown in Figure 10c. The response time and the overshoot amplitude of the PI control are significantly smaller than the feedforward control, which can keep the temperature of the working fluid away from the upper limit and achieve a better system performance. Table 5 shows the results of the settling time and overshoot for the step-down response after $300 \mathrm{~s}$. Compared with the feedforward control, the settling time and overshoot for the evaporation pressure and the mass flow rate of R245fa are both reduced significantly.

Table 5. Comparison of the step response results of the PI and feedforward control strategies.

\begin{tabular}{ccccccc}
\hline \multirow{2}{*}{ Parameter } & \multicolumn{3}{c}{ Settling Time (s) } & \multicolumn{3}{c}{ Overshoot } \\
\cline { 2 - 7 } & Feedforward & PI & Improvement & Feedforward & PI & Improvement \\
\hline Evaporation pressure & 78 & 51 & $34.6 \%$ & 17.62 & 5.01 & $71.6 \%$ \\
R245 mass flow rate & 95 & 41 & $56.8 \%$ & 40.07 & 17.26 & $56.9 \%$ \\
\hline
\end{tabular}

\section{Performance under World Harmonized Transient Cycle (WHTC)}

The actual road conditions are far more complex than the step response. Therefore, the WHTC transient driving cycle with a time length of $1800 \mathrm{~s}$ is used as a case study to analyze the performance of the designed control strategies. The profiles for the engine speed and the engine torque are determined 
according to the requirements of the WHTC transient cycle. Subsequently, the results for the mass flow rate and the temperature of the exhaust gases are calculated by the ICE model built in GT-Power. Figure 11 shows the results as a function of time. The variation trend of the exhaust temperature basically follows the trend of the engine torque, which oscillates more dramatically during the driving cycle. The variation frequency of the mass flow rate is much smaller and shows a strong correlation with the engine speed. The range of the exhaust mass flow rate is between $50 \mathrm{~g} / \mathrm{s}$ and $370 \mathrm{~g} / \mathrm{s}$, and the variation range of the exhaust temperature is $450-900 \mathrm{~K}$.

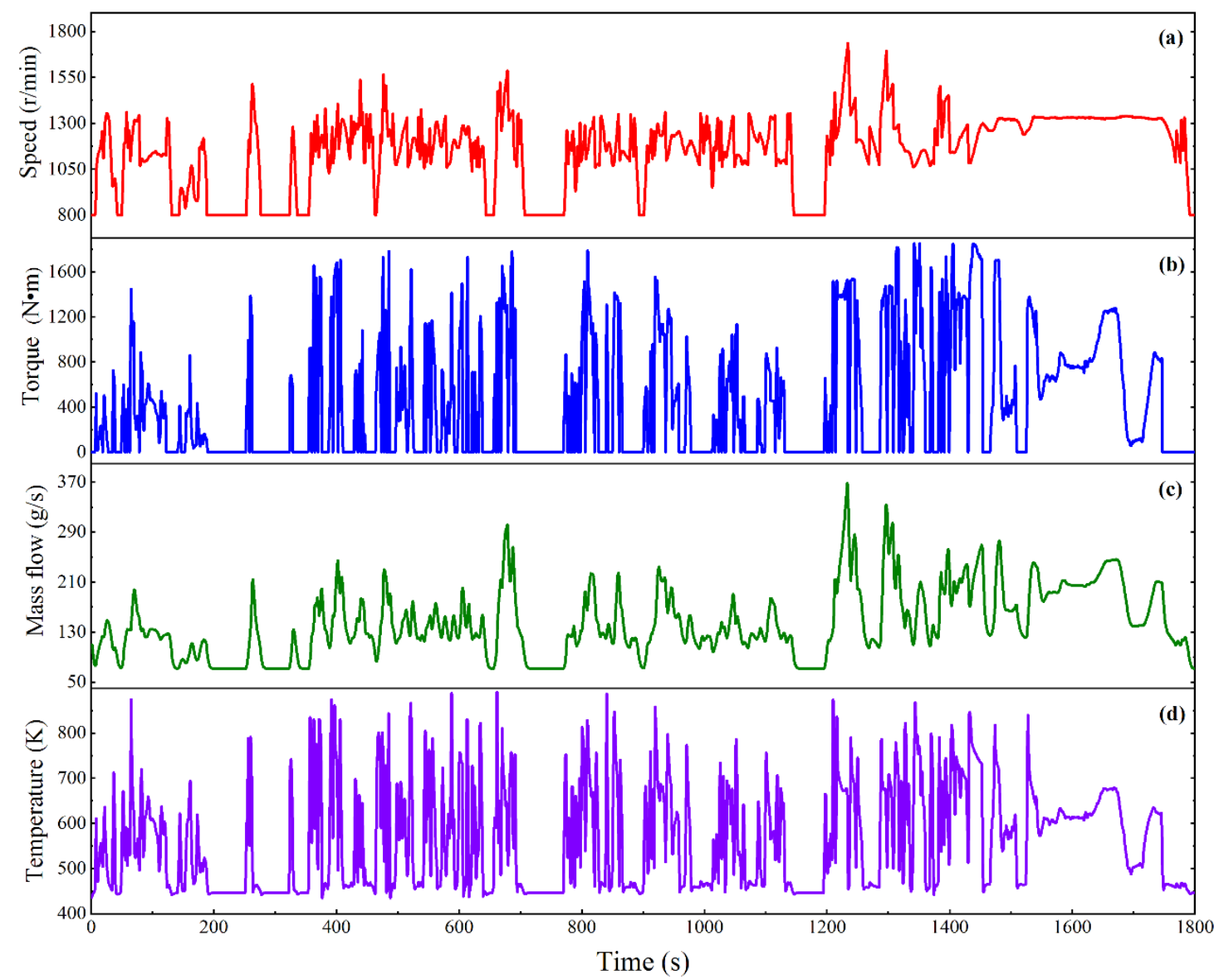

Figure 11. Results for the engine working parameters during the World Harmonized Transient Cycle (WHTC) transient cycle: (a) engine speed; (b) engine torque; (c) exhaust mass flow rate; (d) exhaust temperature.

Figure 12 shows the results for the two controlled variables-the mass flow rate of the working fluid and the evaporation pressure. In this figure, the profile labelled with setpoint is determined based on the static simulation results of the former 63 operating points of the ICE. A linear interpolation algorithm is used to calculate the specific value during the transient driving cycle. Because the frequent changes of engine working conditions, the corresponding mass flow rate and the evaporation pressure of the setpoint profile also change dramatically. The results of the PI control and the feedforward control are displayed as the thick red line and the thick blue dash-dotted line. The mass flow rate varies in a large range from $20 \mathrm{~g} / \mathrm{s}$ to over $300 \mathrm{~g} / \mathrm{s}$. The average mass flow rate under the high-way conditions is greater than that of the urban driving conditions apparently. The evaporation pressure changes from 1 bar to 12 bar during the driving cycle. The average evaporation pressure for the urban conditions is about 4 bar while this value increases to 8 bar for the high-way conditions. 


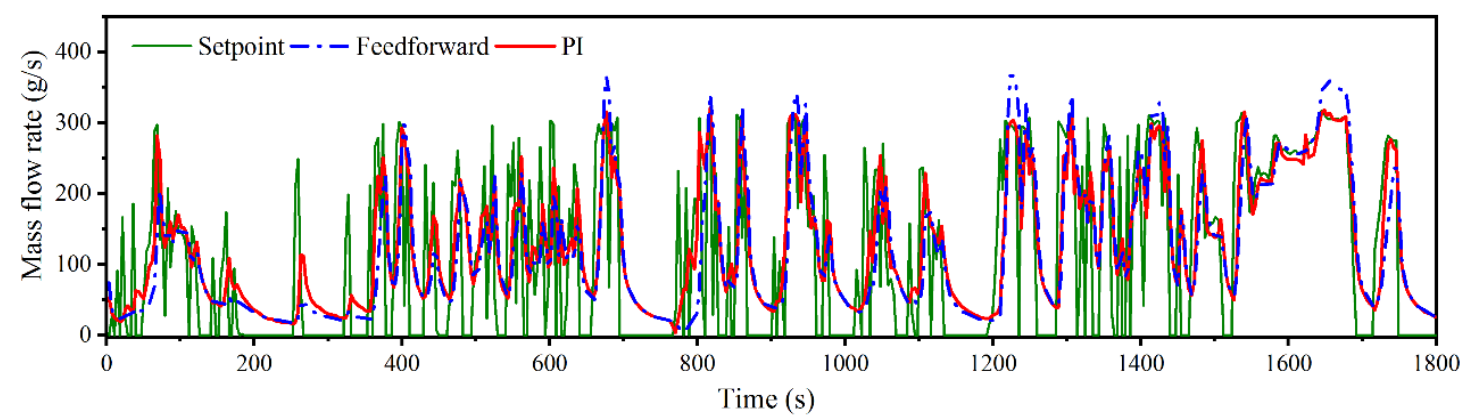

(a)

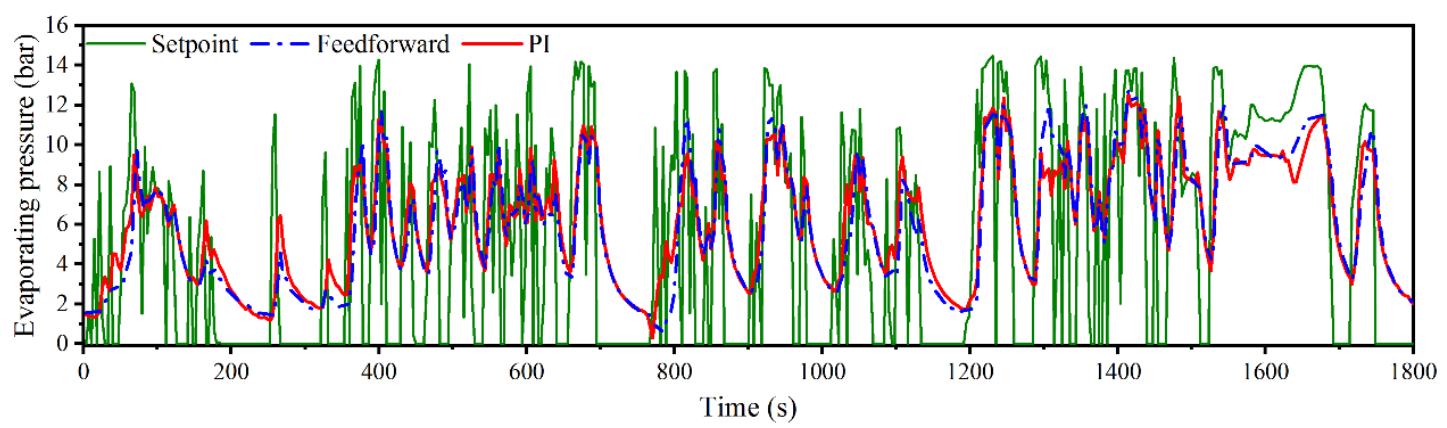

(b)

Figure 12. Results for the controlled variables of the designed control strategies under the WHTC transient cycle: (a) mass flow rate of the working fluid; (b) evaporation pressure.

Compared with the profile of the setpoint, the profiles of the two control strategies are much smoother and the practical variation frequencies are much lower. This is because thermal inertia exists in the ORC system and the mass inertia of the pump and the expander also cause a time delay. This time delay prevents the ORC system following the variation of the engine working conditions immediately while it is helpful for the continuous operation of the ORC system. Basically, the two control strategies show a similar variation trend. However, the closed-loop PI control has a better trace performance for the mass flow rate than the feedforward control. A large overshoot of the mass flow rate by the feedforward control can be observed. The advantage of the PI control for the evaporation pressure is less obvious because the response time of the evaporation pressure is much longer than that of the mass flow rate, which is about two times of the response time of the mass flow rate.

The net power and the thermal efficiency of the ORC system during the WHTC transient cycle are shown in Figure 13, which manifest a similar variation trend with that of the mass flow rate or the evaporation pressure. The net power of the PI control is slightly better than that of the feedforward control for most of the time as displayed by Figure 13a. During the transient driving cycle, the net power varies from 0 to $4.5 \mathrm{~kW}$. The average net power during the high-way conditions is about $3 \mathrm{~kW}$, which is much greater than that of the urban conditions as $1.5 \mathrm{~kW}$. The variation of the thermal efficiency of the ORC system is shown in Figure 13b. The results of the PI control show a higher response time during the driving conditions when the engine power is high. The peak value for the thermal efficiency is also greater than that of the feedforward control during these regions. The maximum thermal efficiency of the PI control exceeds $10 \%$ while the thermal efficiency of the feedforward control is less than $8 \%$ for most of the operation time. This is because the feedback part calculated by the PI control can compensate part of the errors of the mass flow rate during the transient process and the accuracy is improved accordingly. 


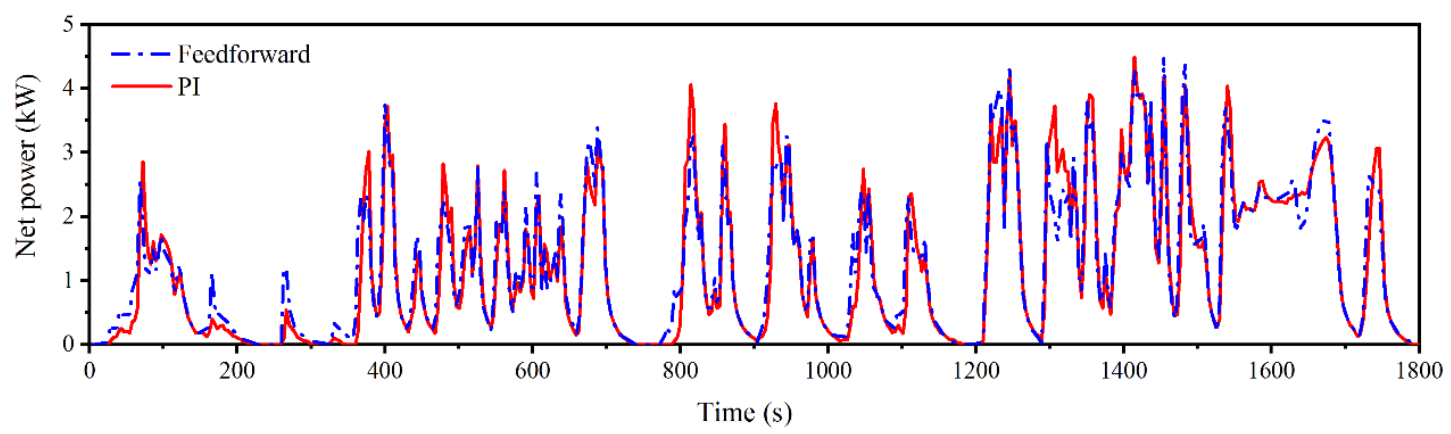

(a)

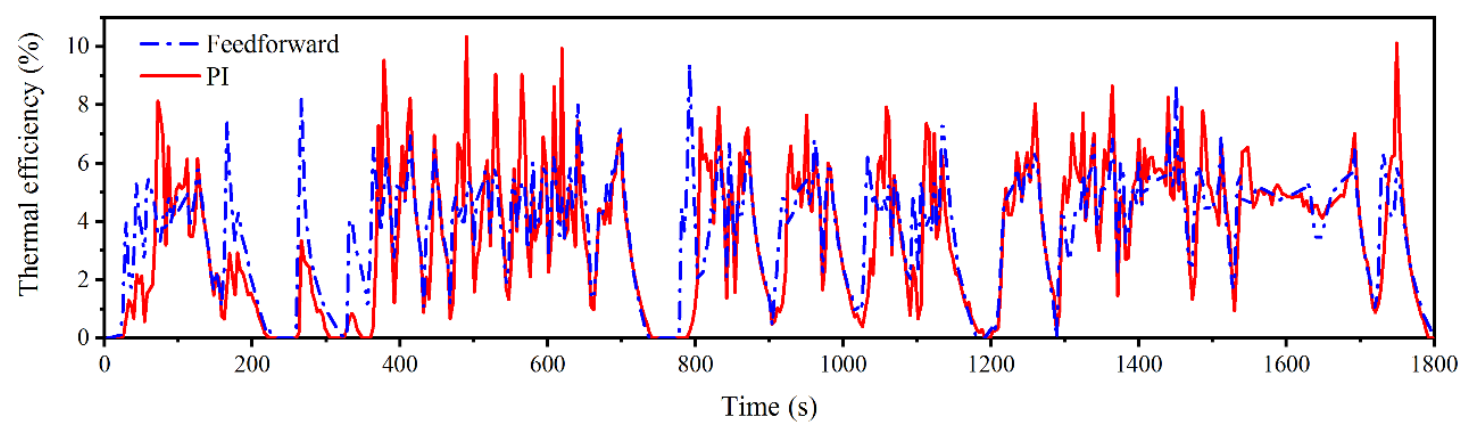

(b)

Figure 13. Comparison of ORC performances between the feedforward control and the PI control under the WHTC transient cycle: (a) net power; (b) thermal efficiency.

Table 6 shows a comparison of the output work and thermal efficiency of the ORC system. The overall WHTC transient driving cycle can be divided to three phases: the urban phase, the suburb phase, and the high-way phase. Each phase takes up $600 \mathrm{~s}$. The ORC performance is improved apparently for the PI control under the urban driving conditions. This is because large fluctuations of the input parameters occur and the PI control can accelerate the response of the ORC system accordingly. For the high-way conditions, the improvement of the PI control is very small, meaning the feedforward control can lead to an acceptable performance under the relatively slow transient processes. During the overall period, the output work of the ORC system using the PI control strategy is increased by $3.23 \%$ and the average thermal efficiency is increased by $2.77 \%$ compared with the feedforward control.

Table 6. Comparison of the ORC system performances between the PI and feedforward controls.

\begin{tabular}{ccccccc}
\hline \multirow{2}{*}{ Phase } & \multicolumn{3}{c}{ Output Work (kWh) } & \multicolumn{2}{c}{ Average Thermal Efficiency (\%) } \\
\cline { 2 - 7 } & Feedforward & PI & Improvement & Feedforward & PI & Improvement \\
\hline Urban & 0.114 & 0.128 & $12.28 \%$ & 3.75 & 4.01 & $6.93 \%$ \\
Suburb & 0.152 & 0.158 & $3.95 \%$ & 4.02 & 4.14 & $2.98 \%$ \\
High-way & 0.322 & 0.321 & $-0.31 \%$ & 4.79 & 4.82 & $0.63 \%$ \\
Overall & 0.588 & 0.607 & $3.23 \%$ & 4.34 & 4.46 & $2.77 \%$ \\
\hline
\end{tabular}

\section{Conclusions}

In this paper, a dynamic model for an ICE-ORC combined system is built in GT-Power. The operation parameters of the ORC system are matched over the entire operation scope of the ICE. Then, two dynamic control strategies including an open-loop feedforward control and a closed-loop PI control are developed in Matlab/Simulink. Based on the WHTC transient driving cycle, the performances of 
the ORC system with the two control strategies are analyzed and compared. The main conclusions are summarized as follows:

1. The evaporation pressure shows a more sensitive influence on the net power of the ORC system than the evaporation temperature. Under the same mass flow rate of the working fluid, the higher the evaporation pressure, the greater the output power. Therefore, to control the ORC system under dynamic conditions, the evaporation pressure is more suitable as a controlled variable than the evaporation temperature. Meanwhile, the mass flow rate should be adjusted to a proper range. If the mass flow rate is too high or too low, a lower evaporation pressure will appear due to lack of enough gaseous working fluid at the outlet of the evaporator.

2. To recover the waste heat of internal combustion engine for vehicle applications, the ORC must be matched across the entire operation scope of the engine. The mass flow rate of the working fluid and the evaporation pressure need to be tuned according to the operation conditions of the engine. Steady-state simulation of the ICE-ORC can help to identify the optimal target values of the mass flow rate and the evaporation pressure when the engine operates under different working conditions. Feedforward control designed based on these optimal values can regulate the working parameters of the ORC under the transient driving conditions.

3. There exists a certain time delay for the ORC system during the transient driving conditions due to the thermal and mass inertia of the system. A closed-loop PI control is added together with the feedforward control. Compared with the feedforward control alone, the response time of the designed closed-loop PI control can be reduced by over $34.6 \%$ and the overshoot of the working parameters of the ORC system during the dynamic process can be reduced by $56.9 \%$. Results indicate that the mass flow rate of the ORC system can follow the variation of the operation conditions of the engine more quickly and the net power output during the urban and suburb road conditions is greater than that of the feedforward control. The average output power and thermal efficiency of the ORC system during the WHTC cycle are improved by $3.23 \%$ and $2.77 \%$, respectively.

For practical applications, there are some other requirements such as the size and weight of the ORC system. In this study, a shell-and-tube evaporator and a plate-type condenser are used. The parameters of these two heat exchangers should be optimized such that a more compact design can be realized. The layout of the overall ORC system is also important and needs to be optimized for practical application. Finally, the output work of the ORC system shows a high fluctuation under transient driving conditions, the designed control strategy needs to be validated by experiments with different road driving conditions and the parameters of the designed PI controller may be tuned slightly. A heat storage system is also helpful to reduce the magnitude of the fluctuation.

Author Contributions: Conceptualization, E.W. and W.Z.; methodology, E.W. and W.Z.; software, W.Z.; validation, E.W., W.Z. and F.M.; formal analysis, W.Z.; investigation, W.Z.; resources, F.Z. and C.Z.; data curation, W.Z.; writing—original draft preparation, W.Z.; writing—review and editing, E.W.; visualization, W.Z.; supervision, C.Z.; project administration, E.W.; funding acquisition, E.W. All authors have read and agreed to the published version of the manuscript.

Funding: This research was funded by the National Natural Science Foundation of China, grant number 51876009.

Conflicts of Interest: The authors declare no conflict of interest.

\section{References}

1. Zhang, J.; Zhang, H.; Yang, K.; Yang, F.; Wang, Z.; Zhao, G.; Liu, H.; Wang, E.; Yao, B. Performance analysis of regenerative organic Rankine cycle (RORC) using the pure working fluid and the zeotropic mixture over the whole operating range of a diesel engine. Energy Convers. Manag. 2014, 84, 282-294. [CrossRef]

2. Yang, F.; Zhang, H.; Song, S.; Bei, C.; Wang, H.; Wang, E. Thermoeconomic multi-objective optimization of an organic Rankine cycle for exhaust waste heat recovery of a diesel engine. Energy 2015, 93, 2208-2228. [CrossRef] 
3. Roy, J.P.; Mishra, M.; Misra, A. Parametric optimization and performance analysis of a waste heat recovery system using Organic Rankine Cycle. Energy 2010, 35, 5049-5062. [CrossRef]

4. Fang, Y.; Yang, F.; Zhang, H. Comparative analysis and multi-objective optimization of organic Rankine cycle (ORC) using pure working fluids and their zeotropic mixtures for diesel engine waste heat recovery. Appl. Therm. Eng. 2019, 157, 113704. [CrossRef]

5. Wang, E.H.; Zhang, H.G.; Fan, B.Y.; Ouyang, M.G.; Zhao, Y.; Mu, Q.H. Study of working fluid selection of organic Rankine cycle (ORC) for engine waste heat recovery. Energy 2011, 36, 3406-3418. [CrossRef]

6. Thurairaja, K.; Wijewardane, A.; Jayasekara, S.; Ranasinghe, C. Working Fluid Selection and Performance Evaluation of ORC. Energy Procedia 2019, 156, 244-248. [CrossRef]

7. Papadopoulos, A.I.; Stijepovic, M.; Linke, P. On the systematic design and selection of optimal working fluids for Organic Rankine Cycles. Appl. Therm. Eng. 2010, 30, 760-769. [CrossRef]

8. Lecompte, S.; Huisseune, H.; Broek, M.V.D.; Vanslambrouck, B.; De Paepe, M. Review of organic Rankine cycle (ORC) architectures for waste heat recovery. Renew. Sustain. Energy Rev. 2015, 47, 448-461. [CrossRef]

9. Liu, X.; Wei, M.; Yang, L.; Wang, X. Thermo-economic analysis and optimization selection of ORC system configurations for low temperature binary-cycle geothermal plant. Appl. Therm. Eng. 2017, 125, 153-164. [CrossRef]

10. Mosaffa, A.H.; Mokarram, N.H.; Farshi, L.G. Thermo-economic analysis of combined different ORCs geothermal power plants and LNG cold energy. Geothermics 2017, 65, 113-125. [CrossRef]

11. Braimakis, K.; Karellas, S. Energetic optimization of regenerative Organic Rankine Cycle (ORC) configurations. Energy Convers. Manag. 2018, 159, 353-370. [CrossRef]

12. Al-Mousawi, F.N.; Al-Dadah, R.; Mahmoud, S. Novel system for cooling and electricity: Four different integrated adsorption-ORC configurations with two expanders. Energy Convers. Manag. 2017, 152, 72-87. [CrossRef]

13. Sadeghi, M.; Nemati, A.; Ghavimi, A.; Yari, M. Thermodynamic analysis and multi-objective optimization of various ORC (organic Rankine cycle) configurations using zeotropic mixtures. Energy 2016, 109, 791-802. [CrossRef]

14. Srinivasan, K.K.; Mago, P.J.; Krishnan, S.R. Analysis of exhaust waste heat recovery from a dual fuel low temperature combustion engine using an Organic Rankine Cycle. Energy 2010, 35, 2387-2399. [CrossRef]

15. Li, L.; Ge, Y.T.; Luo, X.; Tassou, S.A. Experimental investigations into power generation with low grade waste heat and R245fa Organic Rankine Cycles (ORCs). Appl. Therm. Eng. 2017, 115, 815-824. [CrossRef]

16. Xia, G.; Zhang, Y.; Wu, Y.; Ma, C.; Ji, W.; Liu, S.; Guo, H. Experimental study on the performance of single-screw expander with different inlet vapor dryness. Appl. Therm. Eng. 2015, 87, 34-40. [CrossRef]

17. Tian, H.; Shu, G.; Wei, H.; Liang, X.; Liu, L. Fluids and parameters optimization for the organic Rankine cycles (ORCs) used in exhaust heat recovery of Internal Combustion Engine (ICE). Energy 2012, 47, 125-136. [CrossRef]

18. Karellas, S.; Schuster, A.; Leontaritis, A. Influence of supercritical ORC parameters on plate heat exchanger design. Appl. Therm. Eng. 2012, 33, 70-76. [CrossRef]

19. Abam, F.I.; Ekwe, E.B.; Effiom, S.O.; Ndukwu, M.C.; Briggs, T.A.; Kadurumba, C.H. Optimum exergetic performance parameters and thermo-sustainability indicators of low-temperature modified organic Rankine cycles (ORCs). Sustain. Energy Technol. 2018, 30, 91-104. [CrossRef]

20. Quoilin, S.; Aumann, R.; Grill, A.; Schuster, A.; Lemort, V.; Spliethoff, H. Dynamic modeling and optimal control strategy of waste heat recovery Organic Rankine Cycles. Appl. Energy 2011, 88, 2183-2190. [CrossRef]

21. Tong, L.; Enhua, W.; Fanxiao, M.; Xu, Z. Dynamic Simulation of an ICE-ORC Combined System Under Various Working Conditions. IFAC-PapersOnLine 2018, 51, 29-34. [CrossRef]

22. Peralez, J.; Tona, P.; Lepreux, O.; Sciarretta, A.; Voise, L.; Dufour, P.; Nadri, M. Improving the control performance of an Organic Rankine Cycle system for waste heat recovery from a heavy-duty diesel engine using a model-based approach. In Proceedings of the 52nd IEEE Conference on Decision and Control, Florence, Italy, 10-13 December 2013; pp. 6830-6836.

23. Koppauer, H.; Kemmetmüller, W.; Kugi, A. Model predictive control of an automotive waste heat recovery system. Control Eng. Pract. 2018, 81, 28-42. [CrossRef]

24. Feru, E.; Willems, F.; De Jager, B.; Steinbuch, M. Modeling and Control of a Parallel Waste Heat Recovery System for Euro-VI Heavy-Duty Diesel Engines. Energies 2014, 7, 6571-6592. [CrossRef] 
25. Yu, G.; Shu, G.; Tian, H.; Wei, H.; Liu, L. Simulation and thermodynamic analysis of a bottoming Organic Rankine Cycle (ORC) of diesel engine (DE). Energy 2013, 51, 281-290. [CrossRef]

26. Peralez, J.; Tona, P.; Sciarretta, A.; Dufour, P.; Nadri, M. Towards model-based control of a steam Rankine process for engine waste heat recovery. In Proceedings of the IEEE Vehicle Power and Propulsion Conference, Seoul, Korea, 9-12 October 2012; pp. 289-294.

27. Grelet, V.; Reiche, T.; Lemort, V.; Nadri, M.; Dufour, P. Transient performance evaluation of waste heat recovery rankine cycle based system for heavy duty trucks. Appl. Energy 2016, 165, 878-892. [CrossRef]

28. Wei, D.; Lu, X.; Lu, Z.; Gu, J. Dynamic modeling and simulation of an Organic Rankine Cycle (ORC) system for waste heat recovery. Appl. Therm. Eng. 2008, 28, 1216-1224. [CrossRef]

29. Xu, B.; Rathod, D.; Kulkarni, S.; Yebi, A.; Filipi, Z.; Onori, S.; Hoffman, M. Transient dynamic modeling and validation of an organic Rankine cycle waste heat recovery system for heavy duty diesel engine applications. Appl. Energy 2017, 205, 260-279. [CrossRef]

30. Zhao, R.; Zhang, H.; Song, S.; Yang, F.; Hou, X.; Yang, Y. Global optimization of the diesel engine-organic Rankine cycle (ORC) combined system based on particle swarm optimizer (PSO). Energy Convers. Manag. 2018, 174, 248-259. [CrossRef]

31. Liu, T.; Wang, E.; Meng, F.; Zhang, F.; Zhao, C.; Zhang, H.; Zhao, R. Operation Characteristics and transient simulation of an ICE-ORC combined system. Appl. Sci. 2019, 9, 1639. [CrossRef]

32. Yebi, A.; Xu, B.; Liu, X.; Shutty, J.; Anschel, P.; Filipi, Z.; Onori, S.; Hoffman, M. Estimation and Predictive Control of a Parallel Evaporator Diesel Engine Waste Heat Recovery System. IEEE Trans. Control. Syst. Technol. 2017, 27, 282-295. [CrossRef]

33. Gamma Technologies. GT-ISE Users Manual Version 2016; Gamma Technologies, Inc.: Stuttgart, Germany, 2016.

34. Liu, X.; Yebi, A.; Anschel, P.; Shutty, J.; Xu, B.; Hoffman, M.; Onori, S. Model Predictive Control of an Organic Rankine Cycle System. Energy Procedia 2017, 129, 184-191. [CrossRef]

35. Dittus, F.W.; Boelter, L.M.K. Heat transfer in automobile radiators of the tubular type. Int. Commun. Heat Mass Transf. 1985, 12, 3-22. [CrossRef]

36. Shah, M.M. Chart correlation for saturated boiling heat transfer: Equations and further study. ASHRAE Trans. 1982, 88, 185-196.

37. Yan, Y.Y.; Lin, T.F. Evaporation heat transfer and pressure drop of refrigerant R-134a in a small pipe. Int. J. Heat Mass Transf. 1998, 41, 4183-4194. [CrossRef]

38. Zhang, Y.; Wu, Y.; Xia, G.; Ma, C.; Ji, W.; Liu, S.; Yang, K.; Yang, F. Development and experimental study on organic Rankine cycle system with single-screw expander for waste heat recovery from exhaust of diesel engine. Energy 2014, 77, 499-508. [CrossRef] 